\title{
Diagnóstico da irrigação na agricultura familiar de Imperatriz-MA
}

\author{
Jhonata Santos Santana \\ Mestrando em Engenharia Agrícola - Universidade Federal de Lavras - UFLA \\ $\bowtie$ agro.starf@gmail.com \\ Rafael Ferreira Costa \\ Engenheiro Agrônomo, Universidade Estadual do Maranhão - UEMA
}

\section{Wilson Araújo da Silva}

Mestrado em Fitotecnia (Produção Vegetal) - Universidade Federal Rural do Rio de Janeiro - UFRRJ Doutorado em Agronomia (Ciências do Solo) - Universidade Federal Rural do Rio de Janeiro - UFRRJ Professor Adjunto III - Universidade Estadual da Região Tocantina do Maranhão -UEMASUL

\section{Maíra Araújo de Mendonça Lima}

Engenheira Ambiental - Universidade do Estado do Rio de Janeiro

\section{Bruna Magalhães Araujo}

Mestre em Engenheira Ambiental - Universidade do Estado do Rio de Janeiro - PEAMB/UERJ

\section{Resumo:}

$\mathrm{Na}$ agricultura existe uma grande demanda por água, pois não há produção agrícola semeste recurso e devido à sua necessidade para a produção ocorre muitas vezes o uso de forma irracional, superdimensionando as lâminas aplicadas nos cultivos agrícolas, o que acaba tornando esse recurso cada vez mais escasso. Nesse contexto, é imprescindível que o manejo da irrigação seja feito de forma correta através de práticas sustentáveis que garantam a alta produtividade sem que haja o desperdício. Assim, este estudo teve como objetivo identificar os principais aspectos relacionados ao uso da água de irrigação por agricultores familiares do projeto Cinturão Verde em Imperatriz - MA e informa-los sobre a importância do seu uso consciente. Para isso foi elaborado umdiagnós tico rápido participativo (DRP), como objetivo de caracterizar o uso da água pelos agricultores. Os resultados do DRP evidenciaram a necessidade dos agricultores que fazem parte do projeto em conhecer a quantidade e o momento correto de aplicar água em suas culturas, pois observou-se que estão irrigando suas culturas de forma não sustentável e, como objetivo de auxilia-los, determinou-se, para todos os meses do ano a demanda hídrica das principais culturas de interesse econômico do projeto Cinturão Verde, fornecendo dados importantes para auxiliar técnicos e produtores no manejo da irrigação dessas cultura.

Palavras-chave: Agricultura, Irrigação, Sustentável.

\section{Diagnosis of irrigation in family farming in Imperatriz-MA}

\begin{abstract}
:
In agriculture there is a great demand for water, because there is no agricultural production without this resource and due to its necessity for the production often occurs the use of irrational way, oversizing the applied slides in the agricultural crops, which ends up making this resource more and more scarce. In this context, it is imperative that irrigation management be done correctly through
\end{abstract}


sustainable practices that ensure high productivity without wastage. Thus, this study aimed to identify the main aspects related to the use of irrigation water by family farmers of the Belt-Green project in Imperatriz-MA and inform them about the importance of their conscious use. A participatory rapid diagnosis (DRP) was developed to characterize the use of water by farmers. The DRP results showed the need of the farmers who are part of the project to know the correct amount and timing of applying water to their crops, since it has been observed that they are irrigating their crops in an unsustainable way and, for all months of the year the water demand of the main crops of economic interest of the Green Belt Project was determined, providing important data to assist technicians and producers in the management of irrigation of these crops.

Keywords: Agriculture, Irrigation, Sustainable.

\section{Diagnóstico de riego en agricultura familiar en Imperatriz-MA}

\section{Resumen:}

En la agricultura existe una gran demanda por agua, pues no hay producción agrícola sin este recurso y debido a su necesidad para la producción ocurre muchas veces el uso de forma irracional, sobredimensionando las láminas aplicadas en los cultivos agrícolas, lo que acaba haciendo eserecurso cada uno más escaso. En este contexto, es imprescindible que el manejo de la irrigación sea hecho de forma correcta a través de prácticas sostenibles que garanticen la alta productividad sin que haya el desperdicio. Así, este estudio tuvo como objetivo identificar los principales aspectos relacionados al uso del agua irrigación por agricultores familiares del proyecto Cinturón Verde en Imperatriz MA y se informa sobre la importancia de su uso consciente. Para ello se elaboró un diagnóstico rápido participativo (DRP), con el objetivo de caracterizar el uso del agua por los agricultores. Los resultados del DRP evidenciaron la necesidad de los agricultores que forman parte del proyecto en conocer la cantidad y el momento correcto de aplicar agua en sus cultivos, pues se observó que están irrigando sus cultivos de forma no sostenible y, con el objetivo de auxilia- se determinó para todos los meses del año la demanda hídrica de las principales culturas de interés económico del proyecto Cinturón Verde, proporcionando datos de fundamental importancia para auxiliar técnicos y productores en el manejo del riego de esas culturas.

Palabras clave: Agricultura, Irrigación, Sostenible.

\section{INTRODUÇÃo}

A agricultura irrigada se destaca entre os principais usos da água, sendo responsável por $47 \%$ da retirada dos mananciais e $69 \%$ do consumo total no Brasil (ANA, 2016). No Brasil, os cultivos irrigados representam cerca de $16 \%$ da demanda de alimentos e $35 \%$ do valor de produção (SILVA et al., 2016). A técnica da irrigação é uma alternativa para suprir a carência hídrica das culturas em razão da desuniformidade da precipitação em algumas regiões (CARVALHO et al., 2014).

Contudo, apesar dos seus benefícios a prática da agricultura irrigada, quando mal utilizada pode provocar vários problemas, especialmente a salinização dos solos, que diminui a produtividade das culturas e, contribui para o processo de possível desertificação (LUCAS et al., 2014). De acordo com Medeiros e Arruda (2016) a irrigação possui um papel de destaque, por ser um dos principais segmentos demandantes de água na sociedade e para o uso racional 
e sustentável deste recurso é necessário o conhecimento da demanda hídrica das principais culturas irrigadas regionalmente. Diante disso, o conhecimento da demanda hídrica das culturas é de fundamental importância tanto para o projeto quanto manejo da irrigação, determinando a lâmina de irrigação a ser aplicada de acordo com o clima e as características da cultura (SILVA et al., 2017). Uma das principais formas de se estimar as necessidades hídricas das culturas de interesse econômico é através da evapotranspiração de referência (ETo) associada a coeficientes apropriados denominados coeficientes de cultivo (Kc) (OLIVEIRA et al., 2013).

O emprego de metodologias para a determinação das necessidades hídricas das culturas em suas diferentes fases de desenvolvimento contribui para aumentar a produtividade e a eficiência na utilização dos equipamentos, energia elétrica e recursos hídricos (SANTOS et al., 2014). O conhecimento da demanda hídrica das culturas exerce grande influência nas tomadas de decisões a respeito da necessidade ou não de uso de sistemas de irrigação, da quantidade e momento certo de realizar a irrigação (SOBENKO et al., 2016). Diante disso, o presente estudo teve como objetivo identificar os principais aspectos relacionados ao uso da água de irrigação por agricultores familiares na área do Projeto Cinturão Verde, município de Imperatriz- MA e informá-los sobre a importância da racionalização da água por meio de palestra e distribuição de panfletos que apresentavam dados importantes das necessidades hídricas dos cultivos, que serviram de referência para auxiliar técnicos e produtores no manejo da irrigação das culturas exploradas na área de estudo. Para isso, foi utilizada a equação de Penman Monteith-FAO 56, que é considerado o método padrão da FAO para a estimativa da evapotranspiração de referência (ETo).

\section{MATERIAL E MÉTODOS}

O estudo foi desenvolvido na área do projeto Cinturão Verde no entorno do aeroporto Prefeito Renato Moreira, no município de Imperatriz-MA, onde já existem estrutura e histórico de diversos projetos desenvolvidos em parceria com a Universidade Estadual do Maranhão-UEMA (figura 1). 
Figura 1- Área do projeto Cinturão Verde, em torno do aeroporto de Imperatriz-MA.

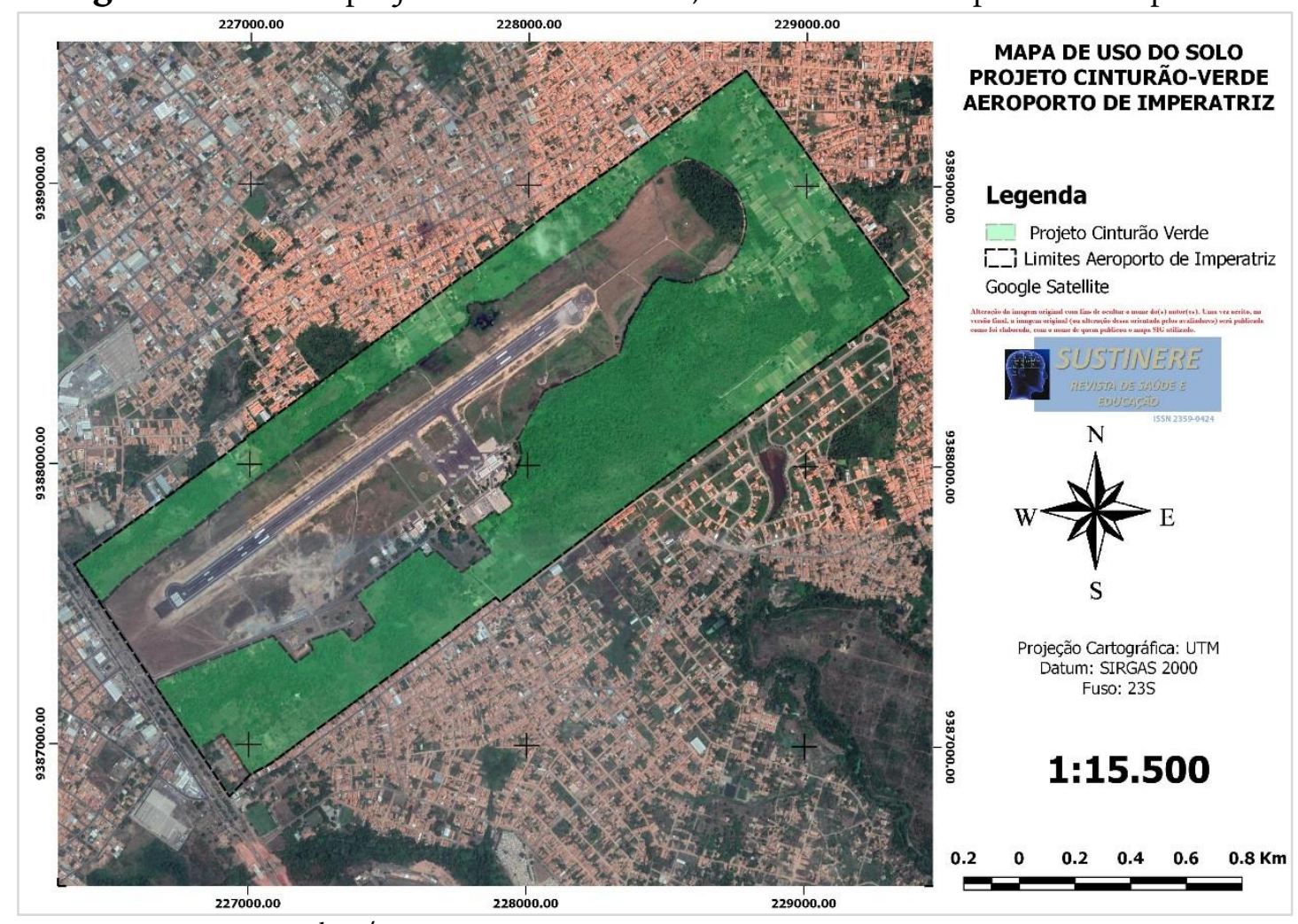

Fonte: Imagem Landsat/Copernicus, 2019.

As coordenadas geográficas da área são $5^{\circ} 31^{\prime} 13^{\prime \prime}$ de latitude S e 47ํㅡㄴ $26^{\prime} 57^{\prime \prime}$ de longitude $\mathrm{W}$, com altitude média de 92 metros acima do nível do mar. O clima segundo a classificação de Köppen é do tipo (Am), tropical quente e úmido, com precipitações mal distribuídas, e duas estações: a da chuva, que vai de dezembro a abril, e a da seca, que vai de maio a novembro.

Segundo o Instituto Nacional de Meteorologia (INMET), a média pluviométrica anual é de 1463,5 mm, a do mês mais chuvoso (março) é de $279 \mathrm{~mm}$ e do mês mais seco (julho) de $6,4 \mathrm{~mm}$. A temperatura média anual é de aproximadamente $26,4{ }^{\circ} \mathrm{C}$ e a umidade relativa média do ar é de aproximadamente $90 \%$.

O solo das propriedades visitadas apresenta textura variando de média a arenosa, com baixa retenção de umidade e altos teores de matéria orgânica, constituindo solo com elevada suscetibilidade à erosão. Nos meses de maior incidência pluviométrica apresenta pontos com drenagem impedida, onde a água tem dificuldade para infiltrar devida uma camada impermeável do solo. 
$\mathrm{Na}$ área onde o estudo foi desenvolvido, os agricultores fazem parte do projeto Cinturão Verde, no qual é voltado para agricultura familiar. Sendo a área explorada por essas famílias desde 1992 após a divisão e concessão da área para cultivo pela INFRAERO. Atualmente estes agricultores contam com água encanada e energia elétrica, onde residem as 56 famílias dos horticultores totalizando 336 pessoas. Para uma melhor caracterização, dos tipos de explorações agrícolas que ocorrem na área destinada ao projeto Cinturão Verde, após a visita de campo, estas foram classificadas em: horticultura, culturas de subsistência, fruticultura, pastagem e áreas sob pousio. As definições de cada classe, estão apresentadas na tabela 1.

Tabela 1- Classificação das explorações agrícolas do projeto Cinturão Verde.

\begin{tabular}{|c|c|}
\hline Classificação & Conceito \\
\hline Horticultura & $\begin{array}{l}\text { Área onde realiza-se o cultivo de plantas hortaliças (alface, } \\
\text { couve-flor, repolho, melancia, pimentões, coentro dentre } \\
\text { outros). }\end{array}$ \\
\hline Culturas de Subsistência & $\begin{array}{l}\text { Área onde ocorre o cultivo cujo o principal objetivo é a } \\
\text { produção de alimentos para garantir a sobrevivência do } \\
\text { agricultor e sua família (mandioca, milho, feijão dentre } \\
\text { outros). }\end{array}$ \\
\hline Fruticultura & Área destinada a produção de frutos para comercialização. \\
\hline & $\begin{array}{l}\text { Área coberta por gramíneas, onde árvores e arbustos são } \\
\text { ausentes. }\end{array}$ \\
\hline Áreas sob pousio & $\begin{array}{l}\text { Áreas onde foram desenvolvidas atividades causando } \\
\text { alteração da vegetação natural. Após o abandono destas, a } \\
\text { vegetação natural começou a se restabelecer, } \\
\text { apresentando-se atualmente em vários estágios } \\
\text { sucessionais. }\end{array}$ \\
\hline
\end{tabular}

Fonte: Os Autores, 2019.

\section{Coleta e tratamento dos dados}

Durante a execução do estudo foram coletados dados por meio da aplicação do DRP, através de uma entrevista semi-estruturada no qual foram feitas 9 perguntas relacionadas ao tema "uso da água de irrigação na agricultura", conforme apresentado na tabela 2. 
Tabela 2- Questionário do Diagnóstico Rápido Participativo. Questionário do Diagnóstico Rápido Participativo (DRP)

$1^{\circ}$. Você mede a quantidade de água (vazão) que aplica na irrigação?

$2^{\circ}$. De onde vem a água que você utiliza em sua propriedade?

3‥ Quantas vezes ao dia você faz irrigação?

4․ Você acredita ser possível minimizar os custos, e a quantidade de água na irrigação, através de tecnologias?

5‥ Você sofre ou já sofreu com a falta de água?

6‥ Como você sabe que aplicou a quantidade correta de água?

7‥ Você tem ideia dos riscos da aplicação em excesso de água nas plantas?

$8^{\circ}$. Quem projetou o seu sistema de irrigação?

Fonte: Os Autores, 2019.

As entrevistas semi-estruturadas foram realizadas com 36 famílias de agricultores, no período de junho de 2017 a novembro de 2018, seguindo um questionário de perguntas abertas para permitir que o informante se expressasse da forma mais espontânea possível, além de facilitar a introdução de outras perguntas que surgem em função da própria conversa, visando sensibilizar a comunidade e também conhecer os principais problemas com relação ao manejo racional da água na agricultura (figura 2).

Figura 2- Aplicação de Diagnóstico Rápido Participativo

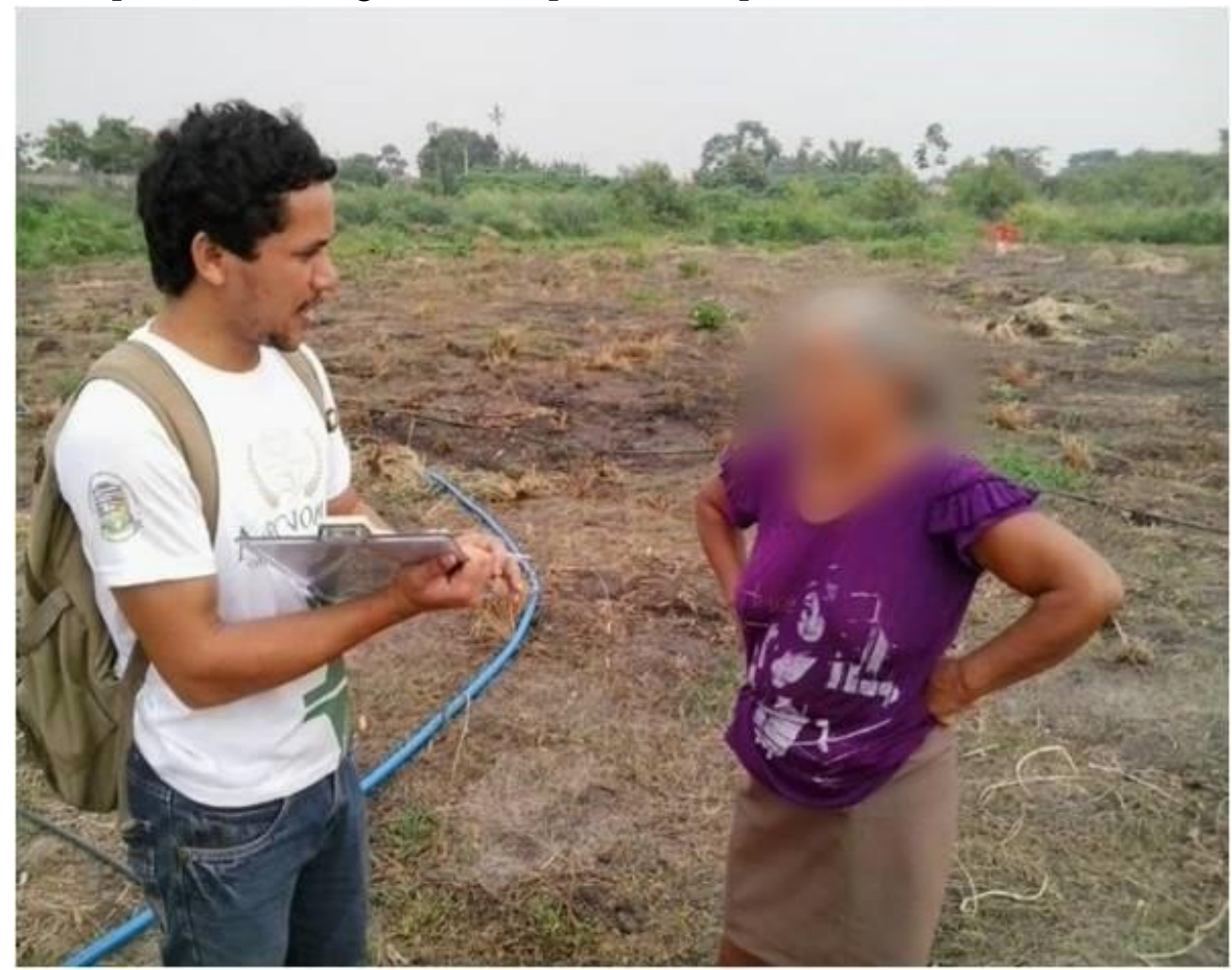

Fonte: Os Autores, 2019. 
A partir das respostas dos produtores foi feita uma análise e uma discussão desse DRP. Durante as visitas realizadas os mais variados cultivos agrícolas foram observados tais como coentro, alface, cebolinha, tomate, pimentão, pimenta, melancia, repolho, couve-flor, milho e feijão. E após essa análise como forma de contribuir com o desenvolvimento sustentável da comunidade, foi decidido elaborar um método prático para o manejo de irrigação das hortaliças cultivadas no projeto Cinturão Verde em Imperatriz-MA

\section{Método do turno de rega calculado}

Apesar de não ser criterioso para efeito de controle da irrigação, o método do turno de rega possibilita o cálculo de vazão, o dimensionamento de tubulações ou canais e a seleção de motobombas em projetos de irrigação. A equação 1 é utilizada para o cálculo do turno de rega (MAROUELLI et al., 1996).

$$
\mathrm{TR}=\frac{\mathrm{CC}-\mathrm{PM}}{10 . \mathrm{ETc}} . \text { Da.f. } \mathrm{z}
$$

em que:

$\mathrm{TR}=$ turno de rega, em dias;

$\mathrm{CC}=$ capacidade de campo, em \% de peso seco;

$\mathrm{PM}=$ ponto de murcha permanente, em \% de peso seco;

$\mathrm{Da}=$ densidade aparente do solo, em $\mathrm{g} / \mathrm{cm}^{3}$;

$Z=$ profundidade efetiva do sistema radicular das plantas em $\mathrm{cm}$;

$\mathrm{f}=$ fator de disponibilidade de água a cultura, decimal.

$\mathrm{ETC}=$ evapotranspiração da cultura, em mm/dia.

Além disso, recomenda-se adotar o período de irrigação 1 dia a menos que o turno de rega, equação 2 (MELLO e SILVA, 2006).

$$
\mathrm{PI}=\mathrm{TR}-1
$$


A textura de um solo é avaliada no campo através do tato, pela sensação ao esfregar um pouco de solo úmido entre os dedos. A areia provoca sensação de aspereza (como areia da praia), o silte (limo) de sedosidade (como talco) e a argila de pegajosidade. Daí surgirem as classes de textura, procurando definir as diferentes combinações de argila, silte e areia. Exemplos: muito argilosa, argilosa, franca (barro), siltosa e arenosa (LEMOS e SANTOS, 1996).

Tabela 3 - Valores* aproximados para CC, PM, Da e outras características físicoshídricas dos solos segundo a sua classe textural.

\begin{tabular}{ccccccc}
\hline Textura do solo & $\begin{array}{c}\mathrm{VIB}^{1} \\
(\mathbf{c m} / \mathbf{h})\end{array}$ & $\begin{array}{c}\mathrm{Da}^{2} \\
\left(\mathrm{~g} / \mathbf{c m}^{3}\right)\end{array}$ & $\begin{array}{c}\mathrm{CC}^{3} \\
\text { (\%peso) }\end{array}$ & $\begin{array}{c}\mathrm{PM}^{4} \\
(\% \text { peso) }\end{array}$ & $\begin{array}{c}\mathrm{CAD}^{5} \\
(\% \text { peso) }\end{array}$ & $\begin{array}{c}\mathrm{CAD}^{6} \\
(\mathbf{m m} / \mathbf{m})\end{array}$ \\
\hline Arenoso & 5 & 1,65 & 9 & 4 & 5 & 85 \\
Franco-arenoso & $(2,5-22,5)$ & $(1,55-1,80)$ & $(6-12)$ & $(2-6)$ & $(4-6)$ & $(70-100)$ \\
& 2,5 & 1,5 & 14 & 6 & 8 & 120 \\
Franco & $(1,3-7,6)$ & $(1,40-1,60)$ & $(10-18)$ & $(4-8)$ & $(6-10)$ & $(90-150)$ \\
& 1,3 & 1,4 & 22 & 10 & 12 & 170 \\
Franco-argiloso & $(0,8-2,0)$ & $(1,35-1,50)$ & $(18-26)$ & $(8-12)$ & $(10-14)$ & $(140-190)$ \\
& 0,8 & 1,35 & 27 & 13 & 14 & 190 \\
Silto-argiloso & $(0,25-1,5)$ & $(1,30-1,40)$ & $(25-31)$ & $(11-15)$ & $(12-16)$ & $(170-220)$ \\
& 0,25 & 1,3 & 31 & 15 & 16 & 210 \\
Argiloso & $(0,03-0,5)$ & $(1,25-1,35)$ & $(27-35)$ & $(13-17)$ & $(14-18)$ & $(190-230)$ \\
& 0,05 & 1,25 & 35 & 17 & 18 & 230 \\
& $(0,01-0,1)$ & $(1,20-1,30)$ & $(31-39)$ & $(15-19)$ & $(16-20)$ & $(200-250)$ \\
\hline
\end{tabular}

Fonte: VERMEIREN; JOBLING, 1997.

* Primeiro valor representa a média e os valores entre parênteses representam a faixa de variação.

${ }^{1} \mathrm{VIB}=$ velocidade de infiltração básica; ${ }^{2} \mathrm{Da}=$ Densidade Aparente; ${ }^{3} \mathrm{CC}=$ umidade do solo na capacidade de campo; ${ }^{4} \mathrm{PM}=$ umidade do solo no ponto de murcha permanente; ${ }^{5} \mathrm{CAD}=$ água total disponível = $(\mathrm{CC}$ - PMP); ${ }^{6} \mathrm{CAD}$ em lâmina de água por profundidade de solo.

Tabela 4 - Profundidade efetiva do sistema radicular (Z) de algumas culturas

\begin{tabular}{cc}
\hline CULTURA & Z (cm) \\
\hline Alface & $15-25$ \\
Cebola & $20-35$ \\
Couve-flor & $20-30$ \\
Feijão & $20-30$ \\
Melancia & $30-40$ \\
Melão & $20-30$ \\
Milho & $30-45$ \\
Pimenta & $25-45$ \\
Pimentão & $30-70$ \\
Tomate & $25-45$ \\
Coentro & $15-25$ \\
Repolho & $20-30$ \\
\hline
\end{tabular}

Fonte: MAROUELLI e BRAGA, 2016.

Para se atingir este objetivo de estimar a Evapotranspiração das Culturas de Interesse Econômico (ETc) exploradas pelas famílias de horticultores do projeto Cinturão Verde foram consultados dados climatológicos da série histórica que abrange os anos de 2005 a 2018, no site do INMET, da região de Imperatriz- MA, pois os dados dessa série histórica apresentavam 
o maior intervalo sem interrupção. A aquação agrometeorológica utilizada para estimar a Evapotranspiração de Referência (ETo), correspondente ao período foi a de Penman-Monteith (ALLEN et al., 1998). A Equação de Penman-Monteith-FAO, é descrita abaixo (equação 3).

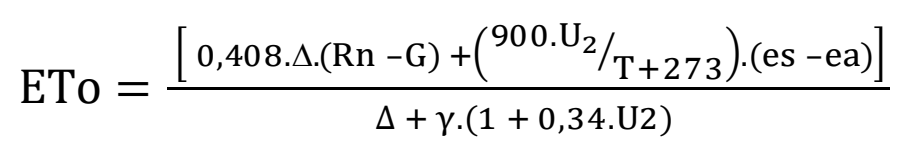

Onde:

ETo - evapotranspiração de referência, $\mathrm{mm} \mathrm{dia}^{-1}$;

$\Delta$ - declividade da curva de pressão de saturação, $\mathrm{kPa}^{\circ} \mathrm{C}^{-1}$;

$\mathrm{Rn}$ - saldo de radiação, $\mathrm{MJ} \mathrm{m}^{-2}$ dia ${ }^{-1}$;

$\mathrm{G}$ - fluxo de calor no solo, $\mathrm{MJ} \mathrm{m}^{-2} \mathrm{dia}^{-1}$;

$\gamma$ - constante psicrométrica, $\mathrm{kPa}^{\circ} \mathrm{C}^{-1}$;

Tméd - temperatura média diária do ar, ${ }^{\circ} \mathrm{C}$;

$\mathrm{U} 2$ - velocidade do vento a $2 \mathrm{~m}$ de altura, $\mathrm{m} \mathrm{s}^{-1}$;

es - pressão de saturação de vapor d'água, kPa;

ea - pressão atual de vapor d'água, $\mathrm{kPa}$.

Também foi utilizado o coeficiente de cultivo (Kc) que é obtido experimentalmente através da relação entre a ETc e a ETo, e representa a integração dos efeitos de quatro características que distinguem a evapotranspiração da cultura da evapotranspiração de referência: a altura da cultura, a resistência do dossel vegetativo, o albedo da superfície cultura-solo e a evaporação da água na superfície do solo (PEREIRA e ALLEN, 1997). Os valores dos coeficientes de cultivo para diversas culturas agrícolas, em suas diferentes fases de desenvolvimento estão disponíveis no boletim FAO-56, conforme a tabela 5 (ALLEN et al.,1998). 
Tabela 5- Kc inicial, médio e final das culturas

\begin{tabular}{cccc}
\hline Culturas & Kc inicial & Kc médio & Kc final \\
\hline Coentro & 0,82 & 1,07 & 0,93 \\
Alface & 0,7 & 1,05 & 1 \\
Cebolinha & 0,7 & 1,05 & 0,75 \\
Tomate & 0,6 & 1,15 & 0,7 \\
Pimentão & 0,4 & 1,1 & 1 \\
Pimenta & 0,4 & 1,1 & 0,9 \\
Melancia & 0,4 & 1 & 0,75 \\
Repolho & 0,7 & 1,05 & 0,95 \\
Couve-Flor & 0,7 & 1,05 & 0,95 \\
Milho & 0,3 & 1,2 & 0,35 \\
Feijão & 0,85 & 1,05 & 1 \\
\hline
\end{tabular}

Fonte: ALLEN et al.,1998.

De posse dos valores da evapotranspiração de referência (ETo) é possível a estimativa do consumo de água de qualquer cultura agrícola de interesse na área do estudo, através da equação 4, descrita abaixo (ALLEN et al.,1998).

$\mathrm{ETc}=\mathrm{Kc} . \mathrm{ETO}$

em que;

ETc $=$ Evapotranspiração da Cultura de interesse econômico $\left(\mathrm{mm} \cdot \operatorname{dia}^{-1}\right)$;

ETo = Evapotranspiração da cultura de referência $\left(\mathrm{mm} \cdot \mathrm{dia}^{-1}\right)$;

Kc = Coeficiente de Cultivo (adimensional), tabelado;

Tabela 6 - Fator de disponibilidade (f) para grupos de cultura em função da evapotranspiração cultura (ETc)

\begin{tabular}{|c|c|c|c|c|c|c|c|c|c|}
\hline \multirow{2}{*}{$\begin{array}{l}\text { Grupo da } \\
\text { Cultura }\end{array}$} & \multicolumn{7}{|c|}{ ETc em mm.dia ${ }^{-1}$} & \multirow[b]{2}{*}{9} & \multirow[b]{2}{*}{10} \\
\hline & 2 & 3 & 4 & 5 & 6 & 7 & 8 & & \\
\hline 1 & 0,500 & 0,425 & 0,350 & 0,300 & 0,250 & 0,225 & 0,200 & 0,200 & 0,175 \\
\hline 2 & 0,675 & 0,575 & 0,475 & 0,400 & 0,350 & 0,325 & 0,275 & 0,250 & 0,225 \\
\hline 3 & 0,800 & 0,700 & 0,600 & 0,500 & 0,450 & 0,425 & 0,375 & 0,350 & 0,300 \\
\hline 4 & 0,875 & 0,800 & 0,700 & 0,600 & 0,550 & 0,500 & 0,450 & 0,425 & 0,400 \\
\hline
\end{tabular}

Fonte: DOORENBOS e KASSAM,1979.

1 - cebola, pimentão, pimenta, alface, batata

2 - banana, repolho, uva, ervilha e tomate

3 - alfafa, feijão, citros, amendoim, abacaxi, girassol, melancia, e trigo

4 - algodão, milho, azeitona, açafrão, sorgo, soja, beterraba, cana-de-açúcar e fumo

*coentro: $\operatorname{adotar} \mathrm{f}=$ grupo 1 ; couve-flor: $\operatorname{adotar} \mathrm{f}=$ grupo 2 ; melão: $\operatorname{adotar} \mathrm{f}=\operatorname{grupo} 3$ 
O turno de rega calculado não deve ser tomado como um valor fixo, mas como uma aproximação ou um guia de irrigação. A lâmina de água necessária para cada irrigação é calculada através da equação 5, (MAROUELLI e BRAGA, 2016).

$$
\text { LRN }=\text { TR. ETc }
$$

em que:

LRN= lâmina de água real necessária, em mm;

$\mathrm{TR}=$ turno de rega, em dias;

ETc= evapotranspiração da cultura, em mm/dia.

Levando-se em conta que a irrigação não é $100 \%$ eficiente, deve-se dividir o valor da LRN pelo índice de eficiência do sistema de irrigação. A eficiência de irrigação depende, dentre outros fatores, das características e do estado de manutenção do sistema, devendo ser avaliada para cada situação específica, tem-se 0,60 a 0,85 para aspersão convencional. Os maiores valores são normalmente verificados em sistemas bem dimensionados, com manutenção adequada e, no caso da aspersão, em condições de pouco vento. A lâmina de água total necessária é dada através da equação 6 (MAROUELLI e BRAGA, 2016).

$$
\mathrm{LTN}=\frac{\mathrm{LRN}}{\mathrm{Ei}}
$$

LTN = lâmina de água total necessária $(\mathrm{mm})$.

LRN= lâmina de água real necessária, em mm;

Ei = eficiência de irrigação (decimal).

O tempo de irrigação quando se irriga usando sistemas por aspersão convencional é determinado através da equação 7 (MAROUELLI e BRAGA, 2016):

$$
\mathrm{Ti}=60 . \frac{\mathrm{LTN}}{\mathrm{Ia}}
$$


Ti = tempo de irrigação (min).

Ia = intensidade de aplicação de água, catálogo do aspersor $\left(\mathrm{mm} \mathrm{h}^{-1}\right)$.

A intensidade de aplicação de água do sistema depende da vazão e do espaçamento entre aspersores, podendo ser obtida no catálogo técnico do aspersor. Preferencialmente, deve ser determinada em testes de campo usando-se a equação 8 (MAROUELLI e BRAGA, 2016):

$$
\mathrm{Ia}=1000 \cdot \frac{\mathrm{Va}}{\mathrm{E}_{\mathrm{A}} \times \mathrm{E}_{\mathrm{L}}}
$$

$\mathrm{Va}=$ vazão do aspersor $\left(\mathrm{m}^{3} \mathrm{~h}-1\right)$.

$\mathrm{E}_{\mathrm{A}}=$ espaçamento entre aspersores ao longo da lateral (m).

$E_{L}=$ espaçamento entre linhas laterais de aspersores $(m)$.

Além disso é necessário observar a disponibilidade de horas de trabalho por dia, e divide-se esse valor pelo tempo de irrigação, com o objetivo de determinar o número total de irrigações a cada turno de rega de acordo com a equação 9 (MELLO e SILVA, 2006).

$$
\mathrm{Nt}=\mathrm{n}^{\circ} \text { de irrigação por dia } \mathrm{x} \text { período de irrigação }
$$

$\mathrm{Nt}=$ número total de irrigações a cada turno de rega

\section{RESULTADOS E DISCUSSÃO}

Através do mapeamento com GPS de navegação, observou-se que a área total destinada ao projeto Cinturão Verde possui uma extensão de $1.692 .256,3 \mathrm{~m}^{2}$, sendo que a área explorada com horticultura é $375.255,78 \mathrm{~m}^{2}$, culturas de subsistência é $148.041,57 \mathrm{~m}^{2}$, fruticultura é $77.028,20 \mathrm{~m}^{2}$, pastagem é $46.032,75 \mathrm{~m}^{2}$ e pousio é $1.045 .898,00 \mathrm{~m}^{2}$. Conforme pode ser visto na figura 4, que apresenta a distribuição espacial das explorações agrícolas do projeto Cinturão Verde. 
Figura 3- Explorações agrícolas do projeto Cinturão Verde, em torno do aeroporto de Imperatriz-MA.

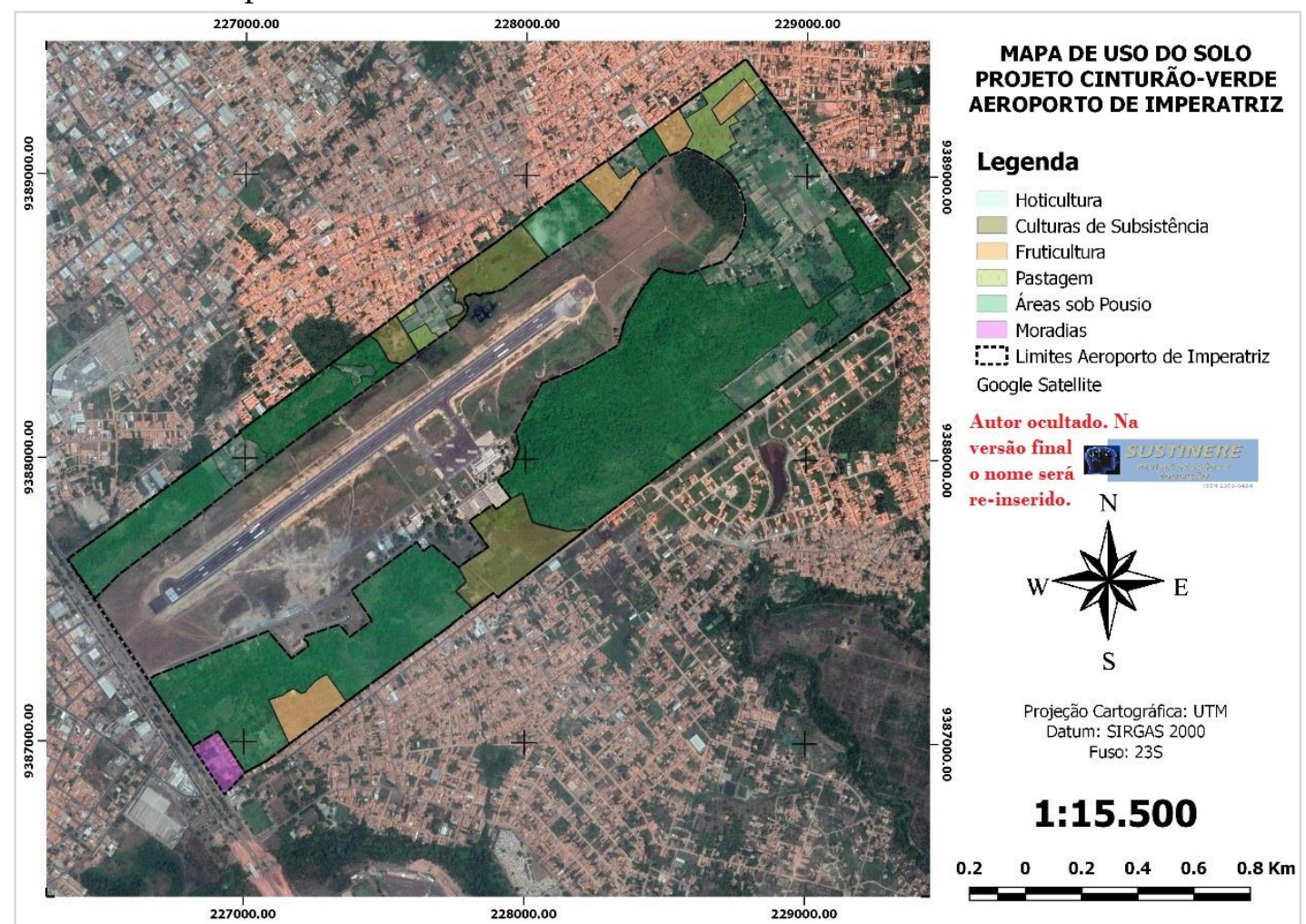

Fonte: Imagem Landsat/Copernicus (2019).

Os resultados apresentados na figura 4 caracterizam a maneira como os produtores estão utilizando a água para realizar a irrigação das culturas. Os resultados foram obtidos a partir da interpretação de suas respostas à entrevista semi-estruturada realizada na comunidade e apresentados Figura 4.

$\mathrm{Na}$ primeira pergunta (figura 4a), buscou-se avaliar se os agricultores tinham algum conhecimento da quantidade de água que eles estavam aplicando em suas culturas. Sendo assim, constatou-se que $100 \%$ afirmaram que não sabiam a quantidade de água que estavam aplicando. Diante dessas respostas, ficou claro a necessidade de construir o conhecimento com esses agricultores, a respeito da quantidade correta da aplicação de água para cultura da área cultivada. Esse resultado corrobora com os estudos de Santana et al., (2018a) pois segundo os autores a maioria dos praticantes da agricultura irrigada no estado do Maranhão, não possuem qualquer conhecimento técnico, sobre a quantidade de água a aplicar, que é muitas vezes baseada no conceito prático do agricultor, o que pode acarretar déficit ou excesso hídrico para as culturas. 
Figura 4- Resultados do Questionário do Diagnóstico Rápido Participativo (DRP).

a) Você mede a quantidade de água (vazão) que aplica na irrigação?

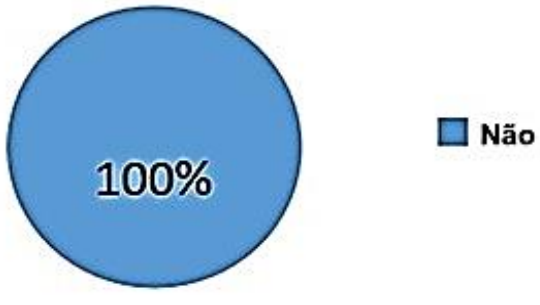

c) Quantas vezes ao dia você faz irrigação?

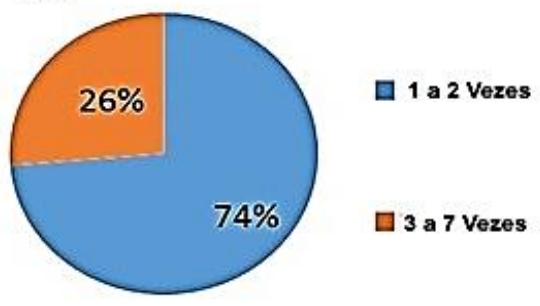

e) Você sofre ou já sofreu com a falta de água?

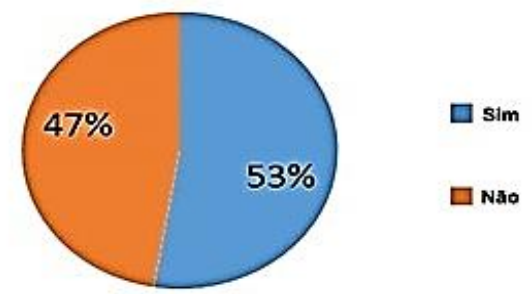

g) Você tem ideia dos riscos da aplicação de água em excesso nas plantas?

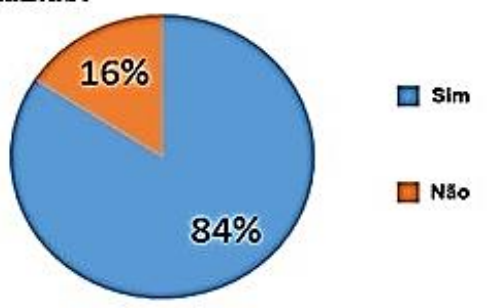

i) Quem projetou o seu sistema de irrigação?

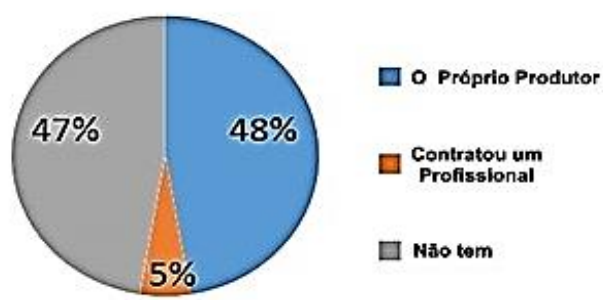

b) De onde vem a água que você utiliza em sua propriedade?

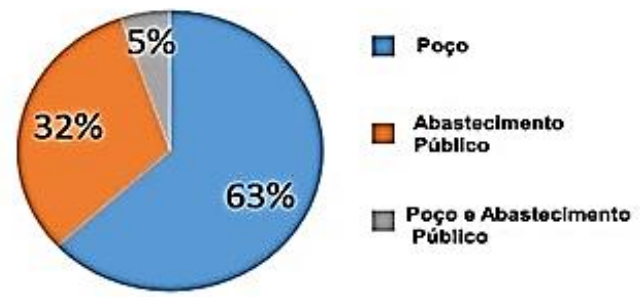

d) Você acredita ser possivel diminuir os custos, e a quantidade de água na irrigação, através de tecnologias?

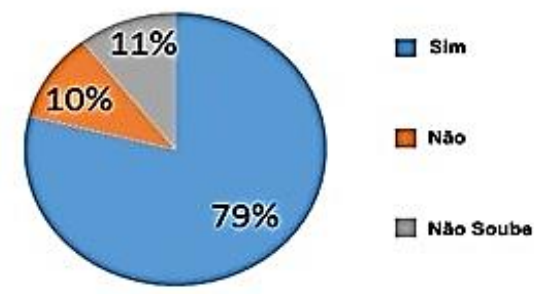

f) Como você sabe que aplicon a quantidade correta de água?

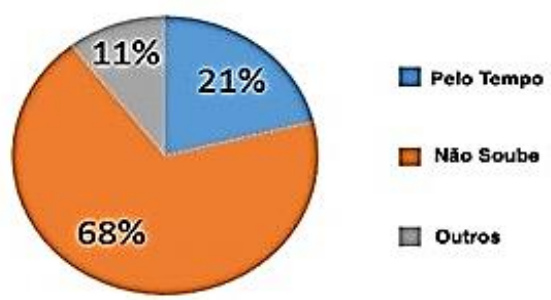

h) Qual o horário que você aplica água nas plantas?

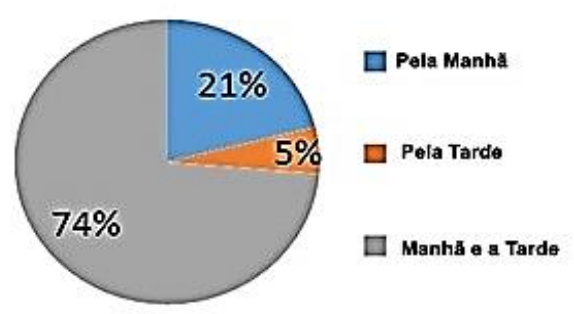

Fonte: Os Autores, 2019. 
Outra informação importante diz respeito à fonte de água que abastece os cultivos, a figura $4 \mathrm{~b}$ apresenta como esse tema é entendido na comunidade pesquisada. Quando os agricultores foram questionados sobre de onde vem a água utilizada na irrigação, $63 \%$ dos entrevistados responderam que utilizam água do poço, 32\% utilizam água do abastecimento público e 5\% utilizam tanto a água do poço quanto a água do abastecimento público para fazer a irrigação de suas culturas. Entretanto, vale ressaltar que na maioria das situações a água utilizada na irrigação dos cultivos na agricultura familiar é, geralmente, proveniente de poços localizados na propriedade ou nas suas proximidades. Sendo mais rara a utilização de água de abastecimento público, principalmente pelo seu alto custo, uma vez que a demanda exigida para este propósito é bastante elevada.

De acordo com a figura 4c, buscou-se avaliar com que frequência os agricultores faziam a irrigação por dia, em suas culturas. $74 \%$ responderam de uma a duas vezes, onde, a maioria destes falaram duas vezes ao dia. $26 \%$ responderam de três a sete vezes por dia, porém todos afirmaram que esta frequência varia com as condições climáticas, pois quando chove a irrigação geralmente é dispensada. Esta informação é de fundamental importância pois segundo Coelho et al., (2005) a lâmina d'água e a maneira como é fornecida às plantas é de suma importância para o sucesso no manejo de uma cultura, pois erros ou negligências nesses pontos muitas vezes geram insucessos da produção tornando os cultivos economicamente inviáveis. As respostas apresentadas pelos agricultores corroboram com as afirmações de Valnir Júnior et al., (2013), que quantidade de água aplicada está relacionada a fatores como às condições específicas de cada localidade, devido as variações climáticas e físico-hídricas dos solos.

Também foi avaliado se os agricultores acreditavam ser possível diminuir os custos, e a quantidade de água na irrigação, através de tecnologias (figura $4 \mathrm{~d}$ ). De acordo com o resultados apresentados, $79 \%$ dos entrevistados responderam que sim, 10\% responderam que não e $11 \%$ ficaram em dúvida, e responderam que não sabem se realmente as tecnologias poderiam contribuir para uma aplicação eficiente da água na agricultura.

Segundo Silva et al., (2017) os principais prejuízos relacionados a aplicação do excesso de água nas culturas é a lixiviação de nutrientes, gastos desnecessários com eletricidade e mão-de-obra. Para Lima et al., (1999) a irrigação utilizada de forma racional pode promover uma economia de aproximadamente $20 \%$ da água e $30 \%$ da energia consumida. Do valor 
relativo à energia, a economia de $20 \%$ seria devido à não aplicação excessiva da água e $10 \%$ devido ao redimensionamento e otimização dos equipamentos utilizados.

A figura $4 \mathrm{e}$ apresenta os resultados obtidos ao se questionar se os agricultores sofrem ou já sofreram com a falta de água. Dentre os entrevistados, 53\% responderam que sim e $47 \%$ responderam que não. Notou-se que esse resultado se deu porque uma boa parte dos produtores utilizam água de poço para fazer irrigação. Logo a disponibilidade de água para estes agricultores que possuem poço em suas propriedades é maior.

Na figura 4f, é possível verificar a resposta dos agricultores quando questionados como eles sabiam que aplicavam a quantidade correta de água. De acordo com os resultados, 21\% responderam que pelo tempo de irrigação, porém de forma empírica, portanto sem comprovação científica, se baseando apenas no conhecimento adquirido através da observação e da experiência. A maior parte dos agricultores, 68\%, responderam que não sabem quanto de água aplicaram nas suas culturas e 11\% responderam que sabem através de outras técnicas, nos quais foram citadas diagnóstico visual da planta e pela umidade do solo. Segundo Bernardo et al., (2008) por não adotar um método de controle da irrigação, o agricultor usualmente irriga em excesso, temendo que a cultura sofra um estresse hídrico, o que pode comprometer a produção e esse excesso tem como consequência o desperdício de energia e de água, usados em um bombeamento desnecessário.

Quando foram questionados sobre os riscos da aplicação de água em excesso nas plantas, $84 \%$ dos agricultores responderam que tinha conhecimento do problemas relacionados ao uso exagerado da água para as plantas e 16\% responderam que não sabiam que o excesso de água causava problemas para suas culturas (figura 4g). De acordo com Lucas et al., (2014) o principal problema relacionado ao excesso de aplicação de água na agricultura são os sais na água, pois o seu acúmulo no solo à medida que a água evapora, pode resultar em salinização do solo e o aumento da salinidade no solo ocasionar a redução no rendimento das culturas e provoca até mesmo a sua morte.

$\mathrm{Na}$ figura $4 \mathrm{~h}$ é possível verificar qual o horário que os agricultores costumam fazer a irrigação. De acordo com os resultados, $21 \%$ responderam que só faziam a irrigação pela manhã, 5\% responderam que só irrigavam a tarde e 74\% dos agricultores responderam que fazem irrigação de manhã e de tarde. Santana et al., (2019), testando cinco frequências de irrigação na cultura do alface em Imperatriz-MA, observaram maior produtividade com a 
lâmina de irrigação correspondente a $125 \%$ da ETc, realizada na frequência de duas irrigações ao dia, sendo uma pela manhã às $05 \mathrm{~h}$ e outra no final da tarde às $17 \mathrm{~h}$ com duração de 5 minutos cada rega.

Sabe-se que a radiação solar e o vento influenciam diretamente na eficiência do aproveitamento da água de irrigação. De acordo com Tagliaferre et al., (2015) a radiação solar é que exerce maior influência na taxa de evapotranspiração dos cultivos, pois o aumento da temperatura do ar é diretamente proporcional ao aumento da radiação solar incidente. 0 vento também exerce grande influência na taxa de evapotranspiração, pois remove o vapor de água da camada de ar acima da superfície evaporante, criando um gradiente de pressão de vapor o que contribui para o acréscimo na demanda atmosférica por vapor d'água (ALLEN et al., 1998; AYOADE, 2006). Assim, nas horas mais quentes do dia o aumento da radiação solar e da velocidade do vento elevam a demanda atmosférica por vapor d'água, reduzindo a quantidade de água disponível para infiltração. Por isso, os horários mais apropriados do dia para a irrigação são no início da manhã ou final da tarde a fim de evitar maiores perdas por evaporação, garantindo maior infiltração dessa água no solo, evitando assim o desperdício (MONTE et al., 2019).

Quando foram questionados, sobre quem projetou o sistema de irrigação da sua propriedade (figura 4i), 48\% dos agricultores responderam o próprio agricultor, $5 \%$ contratou um profissional para dimensionar o seu sistema de irrigação e $47 \%$ dos agricultores ainda não tem um sistema de irrigação na sua propriedade, ou seja, eles ainda fazem a irrigação através de mangueira. Isto pode estar relacionado aos custos com mão-de-obra na implantação do sistema, por isso o agricultor tem preferência por realizar a implantação do seu próprio sistema de irrigação. Após as visitas de campo, constatou-se que o sistema de irrigação mais comum é do tipo aspersão convencional especialmente nas áreas de cultivo de alface, cebolinha, coentro e couve. Entretanto, como a grande maioria desses sistemas de irrigação foram implantados pelos próprios produtores, foi observado que estes não apresentam os critérios técnicos mínimos aceitáveis para uma aplicação uniforme da irrigação. Além disso, se encontram em péssimo estado de conservação devido à falta de manutenção, emissores entupidos, tubulações com vazamentos, mangueiras perfuradas e etc, o que ocasiona desperdício de água, energia e redução da produção. Esse foi um dos temas tratados na 
reunião onde os agricultores foram orientados da importância da manutenção anual dos equipamentos de irrigação e os cuidados constantes para garantir seu bom funcionamento.

O quadro 1 apresenta os principais problemas observados nos sistemas de irrigação, durante a visita na área de estudo, suas causas e dicas de como esses problemas podem ser solucionados.

Quadro 1 - Problemas encontrados durante a visita, possíveis causas e soluções propostas.

\begin{tabular}{|c|c|c|c|}
\hline $\begin{array}{l}\text { Sistema } \\
\quad \text { de } \\
\text { Irrigação } \\
\text { utilizado }\end{array}$ & $\begin{array}{c}\text { Problema } \\
\text { observado } \\
\text { durante a visita }\end{array}$ & Possíveis causas & Soluções propostas \\
\hline \multirow{4}{*}{$\begin{array}{l}\text { Aspersão } \\
\text { Convencional }\end{array}$} & \multirow[b]{2}{*}{$\begin{array}{l}\text { Crescimento e } \\
\text { produção desuniforme } \\
\text { da cultura dentro de } \\
\text { uma mesma área de } \\
\text { cultivo }\end{array}$} & \multirow{2}{*}{$\begin{array}{l}\text { Redução do raio de } \\
\text { alcance do jato d'água } \\
\text { pois durante a } \\
\text { instalação do sistema } \\
\text { não respeitou a pressão } \\
\text { de serviço do aspersor } \\
\text { indicada no catálogo }\end{array}$} & $\begin{array}{l}\text { Averiguar, calibrar e padronizar a } \\
\text { velocidade de rotação do aspersor. } \\
\text { Quando a velocidade está muito } \\
\text { alta diminui a trajetória da gota } \\
\text { d'água. }\end{array}$ \\
\hline & & & $\begin{array}{l}\text { Averiguar a pressão do aspersor } \\
\text { colocando uma tomada de pressão } \\
\text { no tubo de elevação logo abaixo do } \\
\text { aspersor. O aspersor deve } \\
\text { trabalhar na pressão de serviço } \\
\text { sugeridas no catálogo fabricante, } \\
\text { pois pressões diferentes das } \\
\text { recomendadas influenciam no } \\
\text { alcance da gota d'água. }\end{array}$ \\
\hline & $\begin{array}{l}\text { Escoamento } \\
\text { Superficial da água na } \\
\text { área de cultivo }\end{array}$ & $\begin{array}{l}\text { Aplicação da água com } \\
\text { volume maior do que a } \\
\text { capacidade de } \\
\text { infiltração do solo }\end{array}$ & $\begin{array}{l}\text { Antes de instalar o sistema, } \\
\text { realizar o teste da velocidade de } \\
\text { infiltração da água no solo, pelo } \\
\text { método de infiltrômetro de anel, } \\
\text { para decidir escolher o melhor } \\
\text { aspersor para a área de cultivo. }\end{array}$ \\
\hline & $\begin{array}{l}\text { Encharcamento por } \\
\text { vazamento } \\
\text { subterrâneo. }\end{array}$ & $\begin{array}{l}\text { Rachaduras nas } \\
\text { mangueiras e } \\
\text { tubulações causadas por } \\
\text { estouros devido alta } \\
\text { pressão do sistema ou } \\
\text { falta de manutenção. }\end{array}$ & $\begin{array}{l}\text { Instalar manômetros na saída do } \\
\text { sistema motor-bomba com o } \\
\text { objetivo de verificar a pressão do } \\
\text { sistema e fazer o manejo correto } \\
\text { de irrigação por setores, além de } \\
\text { realizar a manutenção anual das } \\
\text { mangueiras e tubulações para } \\
\text { garantir seu bom funcionamento }\end{array}$ \\
\hline
\end{tabular}

Fonte: Os Autores, 2019.

O primeiro passo é a determinação da evapotranspiração de referência (ETo) que é essencial para o manejo correto da água na agricultura, pois é o principal parâmetro empregado na estimativa de demanda hídrica das culturas que é a base para o adequado manejo dos sistemas de irrigação (SANTANA et al., 2018). A tabela 7 apresenta a estimativa dos 
valores médios mensais de ETo obtidos para a região de estudo, considerando a série histórica de 13 anos de observação e também a média de ETo de todo o período considerado no estudo.

Tabela 7- Média mensal da ETo de 2005 - 2018 de Imperatriz - MA (mm.dia-1).

\begin{tabular}{cccccccccccc}
\hline Jan & Fev & Mar & Abr & Mai & Jun & Jul & Ago & Set & Out & Nov & Dez \\
\hline 4,42 & 4,18 & 4,44 & 4,46 & 5,03 & 5,53 & 6,73 & 7,90 & 8,86 & 7,32 & 5,26 & 4,41 \\
\hline \multicolumn{10}{l|c|}{ Média Geral }
\end{tabular}

Fonte: Os Autores, 2019.

A tabela 7 mostra que para a série histórica avaliada, os meses de agosto, setembro e outubro, respectivamente, apresentaram os maiores valores de ETo mensal, assim, as maiores demandas hídricas das culturas geralmente ocorrem nesse período. Este fato comprova que as necessidades de consumo de água das culturas agrícolas são altamente influenciada pelo clima, devido à sazonalidade, corroborando com a necessidade de dimensionamento e manejo dos sistemas de irrigação a partir de dados locais, evitando sub ou superdimensionamento das lâminas aplicadas nos diferentes cultivos. A partir dos valores de ETo apresentados na tabela 02 foi possível estimar os valores de ETc (Evapotranspiração das culturas de interesse econômico) para as diferentes culturas de interesse exploradas no projeto Cinturão Verde. 0 quadro 2 apresenta os valores obtidos.

Quadro 2 -Valores de evapotranspiração inicial, média e final das culturas (mm.dia- ${ }^{1}$ ) para Imperatriz-MA.

\begin{tabular}{|c|c|c|c|c|c|c|c|c|c|c|c|c|c|c|c|c|c|c|}
\hline \multirow{2}{*}{ Cultura } & \multicolumn{3}{|c|}{ Janeiro } & \multicolumn{3}{|c|}{ Fevereiro } & \multicolumn{3}{|c|}{ Março } & \multicolumn{3}{|c|}{ Abril } & \multicolumn{3}{|c|}{ Maio } & \multicolumn{3}{|c|}{ Junho } \\
\hline & Etci & Etcm & Etcf & Etci & Etcm & Etcf & Etci & Etcm & Etcf & Etci & Etcm & Etcf & Etci & Etcm & Etcf & Etci & Etcm & Etcf \\
\hline Coentro & 3,62 & 4,73 & 4,11 & 3,43 & 4,48 & 3,89 & 3,64 & 4,75 & 4,13 & 3,66 & 4,77 & 4,15 & 4,13 & 5,38 & 4,68 & 4,54 & 5,92 & 5,15 \\
\hline Alface & 3,09 & 4,64 & 4,42 & 2,93 & 4,39 & 4,18 & 3,11 & 4,66 & 4,44 & 3,12 & 4,68 & 4,46 & 3,52 & 5,28 & 5,03 & 3,87 & 5,81 & 5,53 \\
\hline Cebolinha & 3,09 & 4,64 & 3,32 & 2,93 & 4,39 & 3,14 & 3,11 & 4,66 & 3,33 & 3,12 & 4,68 & 3,35 & 3,52 & 5,28 & 3,77 & 3,87 & 5,81 & 4,15 \\
\hline Tom ate & 2,65 & 5,08 & 3,09 & 2,51 & 4,81 & 2,93 & 2,67 & 5,11 & 3,11 & 2,68 & 5,13 & 3,12 & 3,02 & 5,79 & 3,52 & 3,32 & 6,36 & 3,87 \\
\hline Pim então & 1,77 & 4,86 & 4,42 & 1,67 & 4,60 & 4,18 & 1,78 & 4,89 & 4,44 & 1,78 & 4,91 & 4,46 & 2,01 & 5,54 & 5,03 & 2,21 & 6,09 & 5,53 \\
\hline Pim enta & 1,77 & 4,86 & 3,98 & 1,67 & 4,60 & 3,76 & 1,78 & 4,89 & 4,00 & 1,78 & 4,91 & 4,01 & 2,01 & 5,54 & 4,53 & 2,21 & 6,09 & 4,98 \\
\hline Melancia & 1,77 & 4,42 & 3,32 & 1,67 & 4,18 & 3,14 & 1,78 & 4,44 & 3,33 & 1,78 & 4,46 & 3,35 & 2,01 & 5,03 & 3,77 & 2,21 & 5,53 & 4,15 \\
\hline Repolho & 3,09 & 464 & 4,20 & 2,93 & 4,39 & 3,97 & 3,11 & 4,66 & 4,22 & 3,12 & 4,68 & 4,24 & 3,52 & 5,28 & 4,78 & 3,87 & 5,81 & 5,26 \\
\hline Couve-Flor & 3,09 & 4,64 & 4,20 & 2,93 & 4,39 & 3,97 & 3,11 & 4,66 & 4,22 & 3,12 & 4,68 & 4,24 & 3,52 & 5,28 & 4,78 & 3,87 & 5,81 & 5,26 \\
\hline Milho & 1,33 & 530 & 1,55 & 1,25 & 5,02 & 1,46 & 1,33 & 5,33 & 1,55 & 1,34 & 5,35 & 1,56 & 1,51 & 6,04 & 1,76 & 1,66 & 6,64 & 1,94 \\
\hline Feijão & 3,76 & 4,64 & 4,42 & 3,56 & 4,39 & 4,18 & 3,78 & 4,66 & 4,44 & 3,79 & 4,68 & 4,46 & 4,28 & 5,28 & 5,03 & 4,70 & 5,81 & 5,53 \\
\hline \multirow{2}{*}{ Cultura } & \multicolumn{3}{|c|}{ Julho } & \multicolumn{3}{|c|}{ Ag osto } & \multicolumn{3}{|c|}{ Setembro } & \multicolumn{3}{|c|}{ Outubro } & \multicolumn{3}{|c|}{ Novembro } & \multicolumn{3}{|c|}{ Dezembro } \\
\hline & Etci & Etcm & Etcf & Etci & Ercm & Etcf & Etci & Etcm & Etcf & Etci & Etcm & Etcf & Etci & Etcm & Etcf & Etci & Etcm & Etcf \\
\hline Coentro & 5,52 & 7,20 & 6,26 & 6,48 & 8,45 & 7,34 & 7,27 & 9,48 & 8,24 & 6,00 & 7,83 & 6,81 & 4,31 & 5,63 & 4,89 & 3,61 & 4,71 & 4,10 \\
\hline Alface & 471 & 7,07 & 6,73 & 5,53 & 8,29 & 7,90 & 6,20 & 9,31 & 8,86 & 5,13 & 7,69 & 7,32 & 3,68 & 5,52 & 5,26 & 3,08 & 4,63 & 4,41 \\
\hline Cebolinha & 4,71 & 7,07 & 5,05 & 5,53 & 8,29 & 5,92 & 6,20 & 9,31 & 6,65 & 5,13 & 7,69 & 5,49 & 3,68 & 5,52 & 3,94 & 3,08 & 4,63 & 3,30 \\
\hline Tom ate & 404 & 7,74 & 4,71 & 4,74 & 9,08 & 5,53 & 5,32 & 10,19 & 6,20 & 4,39 & 8,42 & 5,13 & 3,15 & 6,05 & 3,68 & 2,64 & 5,07 & 3,08 \\
\hline Pim então & 2,69 & 7,40 & 6,73 & 3,16 & 8,69 & 7,90 & 3,55 & 9,75 & 8,86 & 2,93 & 8,05 & 7,32 & 2,10 & 5,78 & 5,26 & 1,76 & 4,85 & 4,41 \\
\hline Pim enta & 2,69 & 7,40 & 6,06 & 3,16 & 8,69 & 7,11 & 3,55 & 9,75 & 7,98 & 2,93 & 8,05 & 6,59 & 2,10 & 5,78 & 4,73 & 1,76 & 4,85 & 3,97 \\
\hline Melancia & 2,69 & 6,73 & 5,05 & 3,16 & 7,90 & 5,92 & 3,55 & 8,86 & 6,65 & 2,93 & 7,32 & 5,49 & 2,10 & 5,26 & 3,94 & 1,76 & 4,41 & 3,30 \\
\hline Repolho & 4,71 & 7,07 & 6,39 & 5,53 & 8,29 & 7,50 & 6,20 & 9,31 & 8,42 & 5,13 & 7,69 & 6,96 & 3,68 & 5,52 & 4,99 & 3,08 & 4,63 & 4,19 \\
\hline Couve-Flor & 4,71 & 7,07 & 6,39 & 5,53 & 8,29 & 7,50 & 6,20 & 9,31 & 8,42 & 5,13 & 7,69 & 6,96 & 3,68 & 5,52 & 4,99 & 3,08 & 4,63 & 4,19 \\
\hline Milho & 2,02 & 8,08 & 2,36 & 2,37 & 9,48 & 2,76 & 2,66 & 10,64 & 3,10 & 2,20 & 8,79 & 2,56 & 1,58 & 6,31 & 1,84 & 1,32 & 5,29 & 1,54 \\
\hline Feijão & 5,72 & 7,07 & 6,73 & 6,71 & 8,29 & 7,90 & 7,53 & 9,31 & 8,85 & 6,22 & 7,69 & 7,32 & 4,47 & 5,52 & 5,26 & 3,75 & 4,63 & 4,41 \\
\hline
\end{tabular}

Legenda: ETci $=$ Evapotranspiração Inicial da cultura $\left(\mathrm{mm} \cdot\right.$ dia $\left.^{-1}\right), \mathrm{ETcm}=$ Evapotranspiração média da Cultura $\left(\mathrm{mm} \cdot \mathrm{dia}^{-1}\right)$, ETcf $=$ Evapotranspiração Final da Cultura $\left(\mathrm{mm} \cdot \mathrm{dia}^{-1}\right)$.

Fonte: Os Autores, 2019. 
Método prático para o manejo de irrigação das hortaliças cultivadas no projeto Cinturão Verde em Imperatriz-MA

Para um melhor entendimento da metodologia proposta, um exemplo é apresentado simultaneamente com os passos necessários para se realizar o manejo da água de irrigação. Para tal, será considerado a seguinte situação, apresentado no quadro 3.

Quadro 3 - Exemplo - "Dados a serem considerados"

\begin{tabular}{|c|}
\hline DADOS A SEREM CONSIDERADOS \\
\hline $\begin{array}{l}\text { Cultura: Milho } \\
\text { Fase da cultura: Inicial } \\
\text { Mês: Julho } \\
\text { Sistema de irrigação: aspersão convencional } \\
\text { Eficiência de irrigação (Ei): } 0,80 \text { (sistema bem dimensionado, manutenção adequada e } \\
\text { condição sem vento) } \\
\text { Textura do Solo: Arenosa (avaliada no campo pelo método expedito) } \\
\text { Intensidade de aplicação de água (Ia): } 26,46 \mathrm{~mm} \cdot \mathrm{h}^{-1} \text { (catálogo técnico do aspersor) } \\
\text { Disponibilidade: } 10 \mathrm{~h} \text { de trabalho por dia }\end{array}$ \\
\hline 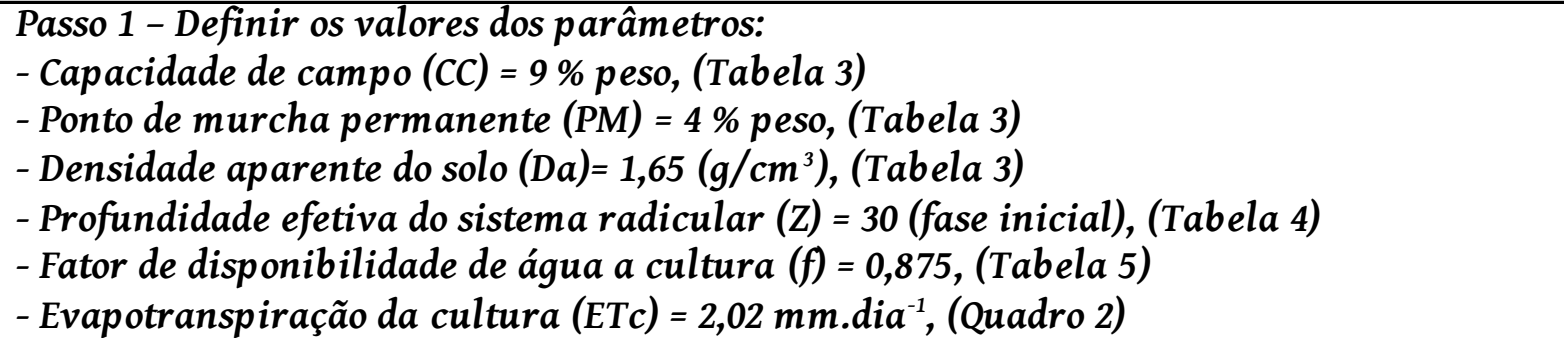 \\
\hline $\begin{array}{l}\text { Passo } 2 \text { - Determinar o turno de rega (TR) e o Período da irrigação (PI) em dias } \\
\qquad T R=\frac{C C-P M}{10 . E T C} \cdot \text { Da.f.z }=\frac{9-4}{10 x 2,02} \cdot 1,65 x 0,875 x 30 \cong 11 \text { dias } \\
P I=T R-1=11-1=10 \text { dias }\end{array}$ \\
\hline $\begin{array}{l}\text { Passo 3- Determinar a lâmina de água necessária para cada irrigação (LRN) e a lâmina de } \\
\text { água total necessária (LTN), em mm. } \\
\qquad L R N=T R . E T c=11 \times 2,02=22,22 \mathrm{~mm} \\
L T N=\frac{L R N}{E i}=\frac{22,22}{0,8}=27,77 \mathrm{~mm}\end{array}$ \\
\hline $\begin{array}{l}\text { Passo 4-Determinar o tempo de irrigação (Ti) } \\
\qquad T i=60 \cdot \frac{L T N}{I a}=60 \cdot \frac{25,25}{26,46} \cong 1 h\end{array}$ \\
\hline $\begin{array}{l}\text { Passo } 5 \text { - Determinações do número de Irrigação por dia } \\
\text { Como só há disponibilidade de 10h de trabalho por dia, serão feitas } 10 \text { irrigações } \\
\text { diárias de } 1 \text { hora. }\end{array}$ \\
\hline $\begin{array}{l}\text { Passo } 6 \text { - Determinações do número total de irrigação a cada turno de rega } \\
N t=n^{\circ} \text { de irrigação por dia x período de irrigação } \\
N t=10 \times 10=100 \text { irrigações durante } 11 \text { dias. }\end{array}$ \\
\hline
\end{tabular}

Fonte: Os Autores, 2019. 
A tabela 8 apresenta um conjunto de práticas e procedimentos que visam determinar a quantidade de água a ser aplicada a cada irrigação e o número de irrigações a serem realizadas a cada turno de rega, que pode ser empregado para as principais culturas de interesse para a microrregião do estudo, fornecendo dados de fundamental importância para auxiliar técnicos e produtores rurais no manejo da irrigação. Uma simples avaliação visual, a partir de uma amostra de solo, sem o uso de qualquer tipo de sensor ou equipamento, fornece aos usuários informações rápidas e suficientes para indicar a necessidade de irrigação da lavoura. Mesmo não sendo altamente preciso, o guia interpretativo sugerido, pode ser utilizado para evitar que as plantas sofram com a falta de água ou que se irrigue em excesso, visando maximizar a produtividade da cultura e minimizar desperdícios. Além disso, o manejo da irrigação a partir de dados de evapotranspiração estimada pelo método de Penman-Monteith-FAO, também se mostra uma boa opção para o uso mais racional da agua na agricultura irrigada em Imperatriz/MA, uma vez que este é considerado, internacionalmente, o mais apropriado para a estimativa da ETo, pois, além de procurar representar, de maneira consistente, o fenômeno biofísico da evapotranspiração, é alimentado por quase todos os elementos meteorológicos observados em estações meteorológicas de superfície (CARVALHO et al., 2011).

\section{CONCLUSÕES}

A influência do estudo se mostrou evidente, devido ao interesse que a comunidade apresentou em ir à reunião para a palestra sobre o tema e responder ao diagnóstico rápido participativo - DRP.

Os resultados do DRP evidenciaram a necessidade dos agricultores em conhecer a quantidade e o momento correto de aplicar água em suas culturas, pois observou-se que estão irrigando suas culturas de forma não sustentável.

O através do estudo foi possível catalogar e determinar para todos os meses do ano a demanda hídrica das principais culturas de interesse econômico exploradas no projeto 
Cinturão Verde, fornecendo dados de fundamental importância para auxiliar técnicos e produtores no manejo da irrigação.

\section{REFERÊNCIAS}

ANA-AGÊNCIA NACIONAL DAS ÁGUAS. Conjuntura dos recursos hídricos no Brasil: Informe 2016. Brasília, DF: ANA. (2016). Disponível em < http://www.snirh.gov.br/portal/snirh/centrais-de-conteudos/conjunturados-recursos-hidricos>. Acesso em: 11 abr. 2019.

ALLEN, R.G.; PEREIRA, L.S.; RAES, D.; SMITH, M. Crop evapatranspiration: Guidelines for computing crop water requirements. Rome: FAO, 1998. 300p. (FAO-irrigation and drainage paper, 56). Disponível em: < https://s3.amazonaws.com/academia.edu.documents/40878584/Allen_FAO1998.pdf?AWSAccessKeyId=AKIAI WOWYYGZ2Y53UL3A\&Expires=1522356472\&Signature $=$ j9t0SOjm\%2B\%2BInw2urflhy0FPKRp4\%3D\&responsecontent-disposition=inline\%3B\%20filename\%3DAllen_FAO1998.pdF>. Acesso em: 12 nov. 2018.

AYOADE, J. O. Introdução á cli matologia para os trópicos. 11 ed. Rio de Janeiro: Bertrand Brasil, 2006. 332p.

CARVALHO, I. R.; DE SOUZA, V. Q.; FOLLMANN, D. N.; NARDINO, M.; SCHMIDT, D.; WESTPHALEN, F \& WESTPHALEN, F. Desempenho agronômico de híbridos de milho em ambiente irrigado e sequeiro. Enciclopédia Biosfera, Goiânia-GO, v. 10, n. 18, p. 1144-1153, 2014. Disponível em: < http://www.conhecer.org.br/enciclop/2014a/AGRARIAS/desempenho\%20agronomico.pdf>. Acesso em: 12 nov. 2018.

CARVALHO, L. G.; RIOS, G. F. A.; MIRANDA, W. L.; NETO, P. C. Evapotranspiração de referência: uma abordagem atual de diferentes métodos de estimativa. Pesquisa Agropecuária Tropical, Goiânia, v. 41, n. 3, p. 456-465, jul./set. 2011. Disponível em: < http://dx.doi.org/10.5216/pat.v41i3.12760>. Acesso em: 12 nov. 2018.

COELHO, E. F.; COELHO FILHO, M. A.; OLIVEIRA, S. L de. Agricultura irrigada: eficiência de irrigação e de uso de água. Bahia Agrícola., v.7, n.1, p.57- 60, 2005 . Disponível em: < http://ufrb.edu.br/neas/images/Artigos_NEAS/2005_3.pdf>. Acesso em: 23 jun. 2019.

DOORENBOS, J.; KASSAM, A. H. Efectos del agua en el rendimento de los cultivos. Roma:FAO, 1979. 212 p. (Estudio FAO riego y drenage, 33).

LEMOS, R.C.; SANTOS, R.D. Manual de descrição e coleta de solo no campo. Campinas: Sociedade Brasileira de Ciência do Solo, 1996

LIMA, J. E. F. W.; FERREIRA, R. S. A.; CHRISTOFIDIS, D. O uso da irrigação no Brasil: 0 estado das águas no Brasil. Brasília: Agência Nacional de Energia Elétrica, 1999. Disponível em: < http://www.iica.org.uy>. Acesso em: 17 Abr. 2018.

LUCAS, A. A. T., MOURA, A. S. A., NETTO, A. D. O. A., FACCIOLI, G. G., \& DE SOUSA, I. F. Qualidade da água no Riacho Jacaré, Sergipe Brasil usada para irrigação. Revista Brasileira de Agricultura Irrigada-RBAI, v. 8, n. 2, p. 98-105, 2014. Disponível em < http://www.inovagri.org.br/revista/index.php/rbai/article/view/228>. Acesso em: 12 nov. 2018.

MEDEIROS, G. A.; ARRUDA, F. B. Avaliação do consumo de água pela irrigação: Parametrização do coeficiente de cultura em função do desenvolvimento da planta. Sínteses: Revista Eletrônica do SIMTEC, n. 1, p. 135-135, 2016. Disponível em: < http://www.sbu.unicamp.br/seer/ojs/index.php/simtec/article/view/9004>. Acesso em: 12 nov. 2018. 
MAROUELLI, W. A.; BRAGA, M. B. Método prático do tato-aparência do solo para manejo de irrigação em hortaliças. Embrapa Hortaliças-Circular Técnica (INFOTECA-E), 2016. Disponível em: < https://www.researchgate.net/publication/313771172_Metodo_Pratico_do_TatoAparencia_do_Solo_para_Manejo_de_Irrigacao_em_Hortalicas>. Acesso em: 12 nov. 2018.

MAROUELLI, W. A.; SILVA, W. L. C.; SILVA, H. R. Manejo da irrigação em hortaliças. Brasília: EMBRAPA-SPI, 1996. Disponível em < http://www2.ufac.br/labmec/menu/disciplinas/irrigacao-e-drenagem/materialdidatico/manejo-da-irrigacao-em-hortalicas.pdf>. Acesso em: 12 nov. 2018.

MELLO, J. L. P.; SILVA, L. D. B. IRRIGAÇÃO. Universidade Federal Rural do Rio de Janeiro- Instituto de Tecnologia, Departamento de Engenharia. Rio de Janeiro. 153p. 2006. Disponível em < http://www.ufrrj.br/institutos/it/deng/leonardo/downloads/APOSTILA/Irriga\%E7\%E3o_LICA.pdf>. $\quad$ Acesso em: 12 nov. 2018.

MONTE, B. R., PEREIRA, J. R., BARRANCO, J. F. Á. A AGRICULTURA IRRIGADA NA REGIÃO DO SEMIÁRIDO LEGAL MINEIRO: UM ESTUDO SOBRE OS AVANÇOS E IMPACTOS AMBIENTAIS. Revista Livre de Sustentabilidade e Empreendedorismo, v. 4, n. 6, p. 222-248, 2019. Disponível em: < http://www.relise.eco.br/index.php/relise/article/download/310/274 >. Acesso em: 12 abr. 2020.

OLIVEIRA, G. M.; LEITÃO, M. M.; DE C BISPO, R.; SANTOS, I.; DE A, L.; CAIO, B \& DE CARVALHO, A. R. Coeficiente de cultura e produtividade da cebola submetida a diferentes lâminas de irrigação. Revista Brasileira de Engenharia Agricola e Ambiental-Agriambi, v. 17, n. 9, 2013. Disponível em: < http://www.agriambi.com.br/revista/v17n09/v17n09a09.pdf>. Acesso em: 12 nov. 2018.

PEREIRA, L.S; ALLEN, R.G.; Novas aproximações aos coeficientes culturais. Engenharia Agrícola, Jaboticabal, v.3, n.4, p.118-143, set/dez. 1997.

SANTANA, J. S.; LIMA, ELTON F.; SILVA, W. A.; FERNANDES, M. C.; RIBEIRO, M. I. D. Equações de estimativa da evapotranspiração de referência (eto) para a região de Balsas-MA. Enciclopédia Biosfera, v. 15, p. 1-14, 2018. Disponível em: <http://www.conhecer.org.br/enciclop/2018a/agrar/equacoes\%20da\%20estimativa.pdf>. Acesso em: 12 nov. 2018.

SANTANA, J. S.; SILVA, W.A.; LIMA, E. F.; OLIVEIRA, G.C. Análise espaço-temporal da evapotranspiração de referência para o estado do Maranhão. Revista Brasileira de Agricultura Irrigada v.12, nº.5, p. 2866 - 2876, 2018a. Disponível em: < http://www.inovagri.org.br/revista/index.php/rbai/article/view/847/pdf_498>. Acesso em: 12 nov. 2018.

SANTANA, J. S.; NASCIMENTO, C. H. S.; SILVA, C. M.; SILVA, W. A.; DAMASCENA, J. F. Resposta de cultivares de alface sob diferentes lâminas de irrigação e doses de nitrogênio. Enci clopédia Biosfera, v. 16, p. 1332-1346, 2019. Disponível em: <http://www.conhecer.org.br/enciclop/2019a/agrar/resposta.pdf>. Acesso em: 12 nov. 2019.

SANTOS, W. O.; SOBRINHO, J. E.; DE MEDEIROS, J. F.; DE MOURA, M. S. B \& DA COSTA NUNES, R. L. Coeficientes de cultivo e necessidades hídricas da cultura do milho verde nas condições do semiárido brasileiro. Irriga, v. 19, n. 4, p. 559, 2014. Disponível em: < http://irriga.fca.unesp.br/index.php/irriga/article/view/529>. Acesso em: 12 jun. 2019.

SILVA, E. C. R., ALVES, F. B., \& DA SILVA, I. I. S. Agricultura irrigada no contexto amazônico: uma abordagem sistemática do uso da água em uma horticultura no município de Altamira-PA. Revista Internacional de Ciências, v. 6, n. 1, p. 29-43, 2016. Disponível em < https://doi.org/10.12957/ric.2016.22926>. Acesso em: 12 nov. 2018.

SILVA, W. A.; SANTANA, J. S.; DA SILVA, C. M \& NUNES, A. A. Regionalização de coeficiente de cultivo aplicado no planejamento da agricultura irrigada no Estado do Maranhão-Brasil. Engenharia Agrícola, v. 37, n. 5, 2017. Disponível em: < http://www.scielo.br/pdf/eagri/v37n5/1809-4430-eagri-37-05-0953.pdf>. Acesso em: 12 nov. 2018.

SOBENKO, L. R.; FANAYA JÚNIOR, E. D.; SANTOS, O. N. A.; MARQUES, P. A. A. Estimativa da necessidade de irrigação na cultura do milho safrinha em sorriso-mt por métodos agroclimatológicos. Revista Brasileira de 
Milho e Sorgo, v. 15, n. 3, p. 544-557, 2016. Disponível em: < http://rbms.cnpms.embrapa.br/index.php/ojs/article/view/744>. Acesso em: 12 nov. 2018.

TAGLIAFERRE, C.; DE PAUlA, A.; ROCHA, F. A.; CAMPOS, W. V.; GUIMARÃES, D. U. Influência dos elementos meteorológicos na evapotranspiração de referência estimada utilizando-se o irrigâmetro no município de Guanambi-BA. Revista Engenharia na Agricultura, v. 23, n. 3, p. 251, 2015. Disponível em: < https://www.researchgate.net/publication/281737347_Influencia_dos_Elementos_Meteorologicos_na_Evapot ranspiracao_de_Referencia_Estimada_Utilizando-se_o_Irrigametro_no_Municipio_de_Guanambi-BA>. Acesso em: 12 abr. 2020.

VERMEIREN, L.; JOBLING, G. A. Título: Irrigação localizada. Ano de publicação: 1997. Fonte/Imprenta: Campina Grande: UFPB, 1997. Páginas: $184 \quad$ p. $\quad$ Disponível em: < http://www.scielo.br/scielo.php?script=sci_nlinks\&ref=000123\&pid=S01039016200500050000100039\&lng=en>. Acesso em: 12 nov. 2018.

VALNIR JÚNIOR, M., DE LIMA, V. L. A., GOMES FILHO, R. R., DE CARVALHO, C. M., SOARES, F. A. L., \& LIMA, S. C. R. V. Lâminas de irrigação e frequência de aplicação no crescimento do meloeiro. REVISTA BRASILEIRA DE AGRICULTURA IRRIGADA-RBAI, $\quad$ v. $7, \quad$ n. $1, \quad 2013 . \quad$ Disponível em: < http://www.inovagri.org.br/revista/index.php/rbai/article/view/136>. Acesso em: 23 jun. 2019.

(cc)) BY

Este trabalho está licenciado com uma Licença Creative Commons - Atribuição 4.0 Internacional. 